\title{
Editorial
}

\section{Festschrift for William Yule}

Welcome to this special issue of Behavioural and Cognitive Psychotherapy, a Festschrift to mark the retirement of Professor William Yule. The collection of papers here, covering reading problems, parenting and conduct disorder, the effects of war on civilian children, cognitive factors associated with trauma in children, social-cognitive approaches to post traumatic stress, and the assessment of PTSD in children, can only begin to skim the surface of his contribution to clinical child psychology in over 40 years of research, teaching, and - above all - clinical work. It is fitting that such a collection appears in this journal. Bill joined the BABP (later $\mathrm{BABCP}$ ) as a founder member in 1972. Three years later, he and Ray Hodgson began to co-edit the new quarterly BABP Bulletin, the forerunner to Behavioural and Cognitive Psychotherapy. Bill retired as Editor of the Journal in 1984, having helped to develop what started out as a single sheet newsletter into a successful, respected, international scientific publication. He is also a former Chair of the Association, and was made an Honorary Fellow in 1984.

Bill was born in Scotland, and educated at the University of Aberdeen, graduating in Psychology in 1962. The following year, he moved down to London to complete his training in clinical psychology at the Institute of Psychiatry - at that time, a relatively new one-year Diploma course, and the only one of its kind in the country. He was to spend most of his professional life at the Institute of Psychiatry.

Howewer, before joining the staff of the Psychology Department, Bill spent a number of years at the Institute of Education, becoming a Lecturer in Child Development under the mentorship of Jack Tizard. It was Jack who got Bill involved in the seminal Isle of Wight epidemiological studies, out of which emerged the influential early papers on children's reading difficulties (see Rutter and Maughan, this issue). Jack Tizard's approach to research, service provision, and the application of basic research to inform social policy was to have a major influence throughout Bill's career.

Once back at the Institute of Psychiatry in the late 1960s, Bill started what he was to continue for the next 35 years: the combination of compassionate and insightful clinical work, with a rigorous scientific approach to evidence. He was the embodiment of a "scientist-practitioner" long before this was reflected in his professorial title, Professor of Applied Child Psychology.

The breadth of his interests is remarkable. He has worked clinically and published important scientific papers in: the epidemiology of childhood disorders, childhood reading difficulties, the effect of lead on children's development, behavioural treatment of enuresis, anxiety disorders, and phobias (including custard pies and balloons), language development and disorder, behaviour modification for children with learning difficulties, theory of mind in autism, fostering and adoption, conduct disorders, parenting programmes (see Scott, this issue), school refusal, behavioural phenotypes, and memory and information processing in 
childhood depression and anxiety. More recently, he has explored the use of computer-assisted therapy in the treatment of phobias and depression.

But Bill is perhaps best known for his pioneering work on the effects of trauma on children. He became involved in the field early on, long before it was the busy and fashionable area that it has become, and it is telling that his interest arose from his clinical work with child survivors of disasters. His early work helped to chart the territory, and he has led the way since then, becoming one of the most widely-cited researchers in the field. His work ranges from psychosocial models of traumatic stress in adults (see Joseph and Williams this issue), to cognitive approaches in children (see Dalgleish et al. this issue), while his empirical approach to treatment and prevention includes careful evaluation of conventional (CBT) and controversial (EMDR) methods. At the Maudsley Hospital, Bill set up, and is Director of, the Child Traumatic Stress Clinic, where he provides assessment and treatment for traumatized children from South London every working week. But his trauma work also has a truly global reach. In Mostar, Bosnia in the mid 1990s, he was responsible for setting up community-based services for war-affected children on behalf of UNICEF. In Turkey and Greece, and most recently in Bam, Iran, he has set up programmes for child victims of earthquakes. In Sri Lanka, he has been involved for many years in providing help to children affected by the civil war and, more recently, to survivors of the tsunami that devastated the country at the end of last year. With colleagues in Norway (see Dyregrov and Raundalen, this issue), Bill co-founded and is a director of the Children and War Foundation, a charity that seeks to develop and implement empirically-supported psychosocial interventions with war- and disaster-affected children around the world. The Foundation's most recent work has been with children in post-war Iraq. These programmes differ from country to country, depending on local need, but in all of them the philosophy is the same - to create sustainable mental health resources for children and families by transferring evidence-based skills to local practitioners.

This reflects Bill's passion for teaching and training others. Invariably entertaining when lecturing, Bill is happy to "give away" psychology skills, whether it be to school counsellors in Turkey, pedagogues in Bosnia, or colleagues in multi-disciplinary teams at The Maudsley. He has lectured at the Institute to several generations of clinical psychologists and psychiatrists, he played a key role in developing the European Erasmus Programme, and he has supervised with patience and wisdom some $20 \mathrm{PhD}$ students, from places as far afield as Iran and Portugal. Bill made major contributions to the Training Course in Clinical Psychology at the Institute of Psychiatry for many years, and he was Head of the Course from 1982-87.

Alongside this commitment to teaching and training, and his steady output of research papers and books (see Berger this issue), Bill is foremost a gifted clinician with a genuine interest in children and their development. As his clinical trainees and colleagues know, Bill's research programmes have always originated from his direct work with children and families. He has a frank dislike of unnecessarily complicated theorizing, unless theories can guide clinical practice. This healthy irreverence for established wisdom drives his research, and means that he has throughout his career remained open-minded about new ideas and new clinical methods - as long as they are amenable to scientific test, and can be backed up by the evidence.

For most people, this combination of teaching, research, and clinical work would be more than enough for one professional career. But Bill, with characteristic energy and enthusiasm, has done more than his fair share of reviewing grants, refereeing papers, examining courses and $\mathrm{PhDs}$, and serving on editorial boards and government and professional working parties. He is 
a Fellow of the British Psychological Society, and a former member of the BPS Fellowships Committee. He has chaired the Research Ethical Committee at the Institute for many years, and has acted as a consultant to the Metropolitan Police, the British Army, the World Health Organization, and the United Nations. Somehow, in the midst of all this, he also found time to run clinical psychology for the then Special Health Authority - he was Head of Clinical Psychology Services at the Bethlem Royal and Maudsley Hospitals from 1987 until 1994. It was in the years leading up to and during this tenure as Head of Services that Bill earned his justly deserved reputation for staunchly defending and promoting Clinical Psychology as a profession.

Bill's legacy is enormous. It is no exaggeration to say that he was instrumental in establishing clinical child psychology in the UK. Trainees, students, and colleagues have been inspired by his teaching and clinical acumen. Children worldwide have benefited from his no-nonsense, evidence-based approach to intervention. Not least, all of us lucky enough to work with him have benefited, in one way or another, from his warmth and kindness, and his enormous sense of fun and optimism. We wish him all the very best in what promises to be a busy - and globetrotting - retirement.

\author{
Patrick Smith \& Sean Perrin \\ Department of Psychology \\ Institute of Psychiatry, King's College London \\ Tim Dalgleish \\ Medical Research Council \\ Cognition and Brain Sciences Unit, Cambridge \\ Guest Editors
}


